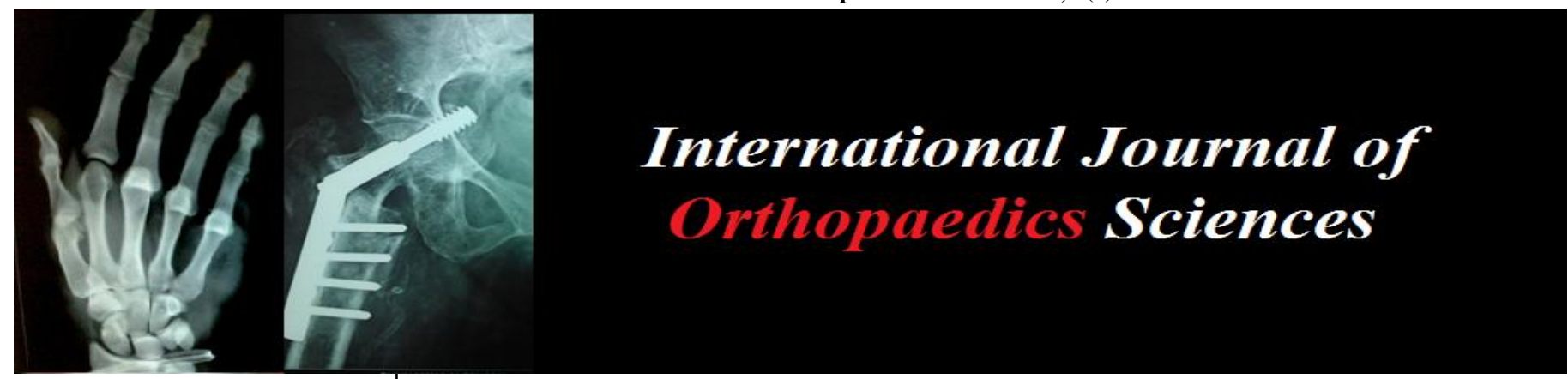

ISSN: $2395-1958$

IJOS 2017; 3(4): 265-270

(C) 2017 IJOS

www.orthopaper.com

Received: 20-08-2017

Accepted: 23-09-2017

Dr. Mukesh S Dwivedi

Assistant Professor, GMERS,

Gotri Medical College, Gotri,

Vadodara, Gujarat, India

Dr. Jitendra Rathva

Senior Resident, GMERS, Gotri

Medical College, Gotri,

Vadodara, Gujarat, India

Dr. Vikas Patel

Senior Resident, GMERS, Gotri

Medical College, Gotri,

Vadodara, Gujarat, India

\section{Open reduction and internal fixation in close middle third fracture clavicle by pre-contoured anatomical clavicle plate: A study of 125 cases}

\author{
Dr. Mukesh S Dwivedi, Dr. Jitendra Rathva and Dr. Vikas Patel
}

DOI: https://doi.org/10.22271/ortho.2017.v3.i4d.38

\section{Abstract}

Introduction: The concept of treating displaced, middle third fractures of clavicle by open reduction and stable fixation thereby restoring the clavicular length is gaining more and more acceptance amongst trauma surgeons. The aim of our study was to analyze the clinical outcome of internal fixation of middle third clavicle fracture by anatomical pre-contoured plate.

Method: 125 patients with isolated displaced middle third clavicle fractures were treated by open reduction and anatomical pre-contoured locking compression plate and followed prospectively till six months after union. All patients were assessed radiologically, clinically and according to disability of arm, shoulder and hand scoring system (DASH).

Results: Average time of union was 8 weeks. Union rate in our study was 97.6\%. Most of the patients returned to pre-injury working status by the end of 10 weeks. Average DASH score at the end of 6 months was 12.

Conclusion: Superiorly placed anatomical pre-contoured locking plate for operative treatment of displaced middle third fractures is a safe and effective option with early return to pre injury working level and at the same time avoiding potential complications of delayed union, non-union and mal-union.

Keywords: clavicle fracture, non-union, mal-union, anatomical clavicle plate

\section{Introduction}

Clavicle fractures are common due to indirect mechanism being fall on an out-stretched hand, accounting for upto $2.6 \%$ to $10 \%$ of all fractures and upto $44.1 \%$ of the fractures involving upper girdle ${ }^{[1]}$. Fractures of middle third account for approximately $80 \%$ of all clavicular injuries. Traditionally, these fractures have been managed non-operatively, even when substantially displaced ${ }^{[2]}$, with good to excellent results ${ }^{[3,4]}$. The limitations of conservatively treated fractures are increased risk of non-union and mal-union resulting in altered biomechanics of upper girdle, cosmetic dissatisfaction and upper extremity weakness ${ }^{[5-8]}$. These factors have caused a gradual shift towards surgical treatment of this fracture ${ }^{[7,9]}$. Many devices have been described for treatment by internal fixation that included circlage wires, Steinmann pins, Kirschner wires, Knowel's pins, Rush rods, Recon plates etc ${ }^{[10-12]}$. The proponents who favor ORIF in these fractures emphasize on early and accurate reduction achieving clavicular length resulting in quicker pain relief and early functional recovery. As the consensus for operative treatment picks-up, recent studies show lower incidence of nonunion and mal-union rates and early return to work compared to conservative treatment ${ }^{\text {[13-18] }}$ With the advent of more advanced anatomically contoured plates, the discussion is shifting from indications for operation to choice of implant for mid shaft clavicle fracture ${ }^{[19-23]}$. This study prospectively evaluates the functional outcome of infra-clavicular approach and superior anatomical clavicle plating for close fractures of middle third clavicle, their advantages and complications in 125 patients.

\section{Materials and Methods}

A prospective study of 125 patients from Jan-2014 to Jan-2017 of close fracture middle third clavicle treated by open reduction and anatomical clavicle plating at GMERS, Gotri medical
Dr. Mukesh S Dwivedi

Assistant Professor, GMERS,

Gotri Medical College, Gotri,

Vadodara, Gujarat, India 
college, Vadodara, a tertiary care centre was undertaken. The study was approved by Ethics committee of our college. Written informed consent of patients was taken before including them in the study.

Inclusion Criteria: Close, displaced middle third clavicle fracture between age group 18yrs to 60yrs. Medically fit patient.

Exclusion Criteria: Fracture associated with neuro-vascular injury, other associated fracture or systemic injury, medically unfit patient, and those patients who refused operative intervention.

Procedure: All patients were evaluated primarily on outdoor basis and other systemic injuries were ruled out. Radiological evaluation included $\mathrm{x}$-ray of both clavicle to assess the extent of shortening on affected side and extent of comminution of fracture. Pre-anaesthetic evaluation and assessment was done and once patients were fit to undergo surgery they were posted for surgery. Beach chair position was given and a bolster in inter-scapular region was placed. Depending on patient's medical condition either regional or general anaesthesia was given. A curved incision was placed inferior to clavicle fracture. Supra-clavicular nerve was carefully identified and protected. Periosteal stripping was avoided as far as possible. Depending upon the extent of comminution one or two inter-fragmentary screws of $2.7 \mathrm{~mm}$ were used to fix them. Once reduction was achieved anatomical clavicle plate of adequate size was applied over the superior surface (Figure -1) and fixed with $3.5 \mathrm{~mm}$ screws. Infra-clavicular vital structures were protected throughout the procedure. Final reduction was assessed using fluoroscopy. Wound was closed in layers, subcuticular suture was taken and sterile dressing was applied. The limb was supported in an arm-sling pouch during the post-operative period. Pendulum exercises were started as pain tolerance of the patient improved. Patient was discharged after first dressing and stitch removal was done on $10^{\text {th }}$ post-operative day. Subsequent follow-ups were at four weeks, eight weeks and six months. At each visit patients were evaluated clinically and radiologically and assessed using DASH scoring system.

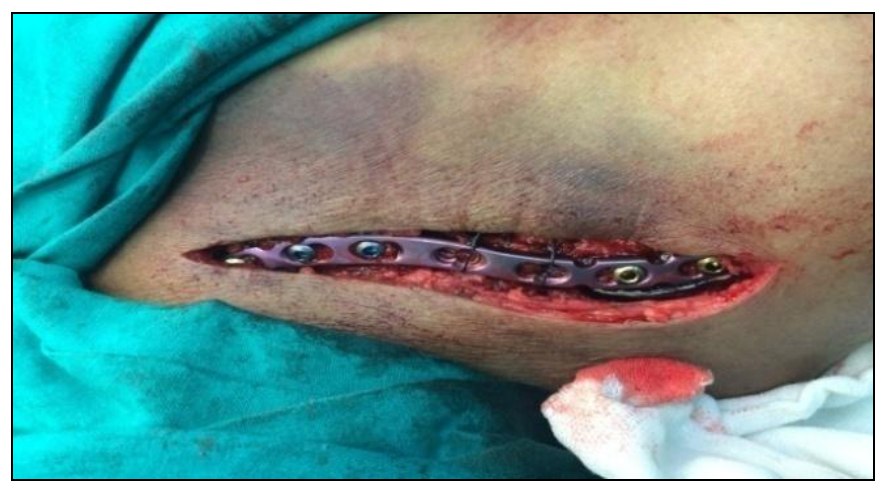

Fig 1: Superior plate placement.

\section{Results}

A total of 125 patients were enrolled in the study from Jan2014 to Jan-2017 as per the inclusion criteria and underwent open reduction and anatomical clavicle plating. 107 were male and 18 were female. 52 fractures were right sided and 73 were left sided. All the patients had indirect mode of trauma that is fall on an outstretched hand. Average age was 33.7 yrs with range from 18 to 60 years. Average admission- operation interval was 3.8 days (range 2 to 7 days). Average duration of post-operative stay was 3.68 days. 5 patients (4\%) had superficial infection which resolved subsequently with regular dressings and antibiotics. 3 patients $(2.4 \%)$ developed delayed deep infection which did not resolve by antibiotics and dressings and necessitated removal of implant. 8 patients had cosmetically unacceptable scar appearance. There was no case of any neuro-vascular complication during intra-op or postoperative phase. All fractures united at an average duration of 8 weeks except 3 cases which went in for non-union. (union rate $97.6 \%$ ). 5 patients had complaint of peri-incisional numbness at 6 months follow-up. 3 patients had implant failure at three months follow-up and required second surgery in form of plating plus bone grafting and subsequently the fracture united at three month follow-up. No patient was advised implant removal at the end of two years. However 8 patients underwent voluntary removal due to cosmetic reasons or due to prominently palpable subcutaneous plate. Most of the patients returned to work by the end of 10 weeks. Average DASH score was 25 at 4 weeks, 20 at 8 weeks, 12 at 6 months. 8 patients had DASH score of more than 20 even after 6 months.

\section{Discussion}

Simple, minimally displaced fractures which have been treated conservatively have consistently given satisfactory results. ${ }^{[3]}$ It is the comminuted, displaced fractures in young healthy active individuals with shortening of clavicle compared to opposite side, who were more prone to nonunion and mal-union and became most frequent indications for surgical treatment. ${ }^{[24-28]}$ The concept of accepting malunion and non-union of clavicle which was earlier thought to be of radiological and academic interest only, not requiring any form of intervention has gradually evolved over to accepting the fact that clavicular mal-union is a distinct clinical identity with radiographic, orthopaedic, neurologic, and cosmetic implications, requiring intervention in some cases. Recent studies have shown increasing evidence that non-operative treatment of displaced mid-shaft fractures of clavicle is not optimal and acceptable as once thought of earlier ${ }^{[5,29,30,25]}$.

Different authors have reported the incidence of non-union and mal-union in conservatively treated fractures. Hill et al reported incidence of $15 \%$ non-union and poor outcome in $31 \%$ cases ${ }^{[5]}$. Nowak et al reported $7 \%$ non-union rate with un-satisfactory outcome in $46 \%$ of their patients [30]. Zlowodzki et al in a meta-analysis of literature found nonunion rate of $15.1 \%{ }^{[28]}$. Sankarenkutty and Turner reported $15 \%$ patients with deformity ${ }^{[31]}$.

Two distinct methods have evolved over years for treatment involving operative intervention in mid shaft fractures. One is IM nailing using flexible nails like rush pins, Kirschner wires, TENS nail etc ${ }^{[11,32]}$. Other method is ORIF using recon plates, DCP, etc. Different authors have compared ORIF using plates and IM nailing and come to varying inferences with one better over the other and some suggesting that there is no significant difference after 12 months in functionaloutcome ${ }^{[33-37,16]}$. Open reduction and plate fixation is superior to IM nailing as it better resists bending and torsional forces that occur during over head abduction of shoulder ${ }^{[38]}$.

Lazarides and Zafiropoulos in their study have suggested that clavicle shortening of more than $18 \mathrm{~mm}$ in males and $14 \mathrm{~mm}$ in females is significantly associated with unsatisfactory results ${ }^{[24]}$. Eskola ${ }^{[39]}$ and associates reported that patients 
with shortening of clavicle segments of more than $15 \mathrm{~mm}$ at follow-up had statistically significantly more pain than those without these findings. Care should be taken to avoid acceptance of shortened clavicle. Restoration of clavicular length is believed to be the pretext for ORIF of clavicle, especially in active younger age group ${ }^{[8,18]}$.

The concept of open reduction and plating in displaced, comminuted, mid-shaft fractures of clavicle is gaining wider acceptance as a preferred method of treatment over intramedullary nailing. Two different plate placements have been studied widely by different authors. Superiorly placed locked compression plate was found to be more biomechanically stable especially in cantilever bending where plate is loaded in tension and fracture fragments are compressed ${ }^{[38]}$. Study by Nathan et al found no difference in union rates while comparing antero-inferior plating and superior plating ${ }^{[40]}$. There was no difference in peri-operative complication in either groups of their series. Placement of plate in either position carries the risk of iatrogenic neuro-vascular injury and neither position had significantly decreased risk ${ }^{[41]}$.

In our study of 125 patients, all were treated by open reduction and superior placement of anatomical pre-contoured locking plate. The average admission- operation interval was 3.8 days. There was no incidence of peri-operative damage to neuro-vascular structures in our study. Average union time in

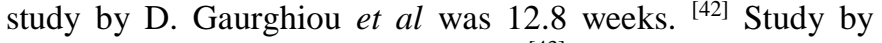
Campochiaro et al and K.R. Reddy ${ }^{[43]}$ showed healing time of 2.3 months and 2.4 months respectively. Average healing time in our study was 8 weeks with a range from 7 weeks to 11 weeks.

Reports of infection in literature range from $0 \%$ to $18 \%$ in different studies ${ }^{[25]}$ Campochiaro et al ${ }^{[22]}$ and Balaji et al(44) reported no case of superficial or deep infection in their study which could possibly be due to their smaller sample size.In our study there were 5 cases of superficial infection $(4 \%)$ which resolved with dressing and antibiotics. 3 patients $(2.4 \%)$ had deep infection in our study.

Dauraiyaswami et al ${ }^{[44]}$ and S. Venkatachalam et al [45] reported $100 \%$ union in their studies which may be due to their small sample size. There was $97.6 \%$ union rate in our study which is similiar to Campochiaro et al who reported union rate of $97.1 \%$. ${ }^{\text {[22] }}$

Chen et al reported incidence of implant failure rate of $7.1 \%$ in their study ${ }^{[32]}$. We had 3 patients of implant failure (incidence of $2.4 \%$ ) at three months follow-up who required second surgery in form of re-plating plus bone grafting and subsequently the fracture united at further follow-up of three months.

Gherghiou et al had 4 patients with hypersensitivity at the scar site ${ }^{[42]}$. In our study 5 patients had peri-incisional numbness at six months follow-up which is comparable to other studies.

Campochiaro et al ${ }^{[22]}$ had 4 cases of hypertrophic scar in their study. We had 8 patients $(6.4 \%)$ having cosmetically unacceptable scar hypertrophy.

Canadian orthopaedic trauma society reported 11 cases out of 62 with hardware irritation or prominence which could possibly be because of use of DCP or recon plate in large number of their patients. ${ }^{[25]} \mathrm{We}$ had 8 patients (incidence $6.4 \%$ ) who underwent implant removal once fracture healed either due to prominently palpable subcutaneous plate or due to cosmetic reasons.

Multicenter trial conducted by Canadian ortho trauma society on 111 patients showed good shoulder function, rapid decrease in pain in post-operative phase, lower incidence of non-union and mal-union rates and overall shorter union time in clavicle fractures treated by open reduction and plating ${ }^{[25]}$. Vander et al found that patients who had surgical intervention had quicker radiological union and returned to work earlier ${ }^{[17]}$. Most of our patients returned to pre-injury work level by the end of 10 weeks.

Gheorghiu et al reported DASH score of 13.4 at 11 months follow-up. ${ }^{[42]}$ Campochiaro et al reported score of 4.8 at the end of 24 months follow-up. ${ }^{\text {[22] }}$ Average DASH score in our study was 25 at 4 weeks, 20 at 8 weeks, and 12 at six months follow-up. This shows that DASH score kept on decreasing with time.

Limitations of Study: We had small data base of patients. No comparision has been done with IM nailing and its outcome or conservative treatment and its outcome. Large and randomized controlled trials are needed to further evaluate the outcome of ORIF with plating. Long term complications need to be evaluated.

\section{Conclusion}

Anatomical pre-contoured locking clavicle plating is a safe procedure with excellent post-operative rehabilitation and early return to pre-injury working status. Stable operative fixation is a effective method to restore shoulder function. ORIF decreases the incidence of delayed union, mal-union and non-union while treating displaced, comminuted fractures of middle third clavicle with more than $20 \mathrm{~mm}$ of shortening. Technique of superior plate placement is safe and can be easily replicated by all orthopaedic surgeons. Subcuticular stitches probably improved the cosmetic appearance and acceptance of scar in most of the patients.

Recommendation: Based on our study we recommend treatment of all comminuted, displaced, middle third shaft fractures of clavicle by open reduction and internal fixation using anatomical pre-contoured locking compression plate.

Conflict Of Interest: The authors have no conflict of interest to declare.

Funding: This study is not supported by any grant whatsoever from any organization or company.

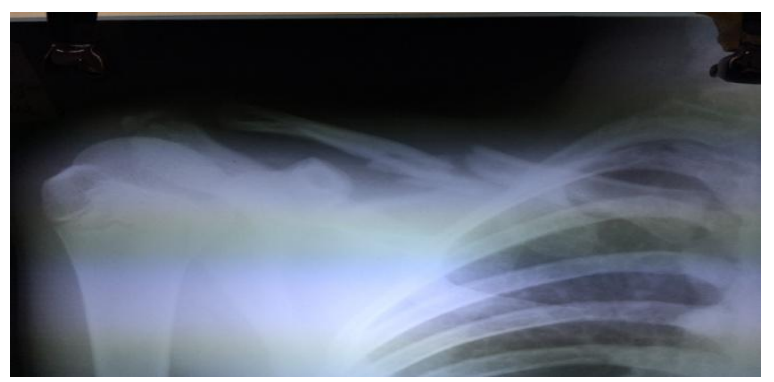

Pre- operative x-ray. (case no21)

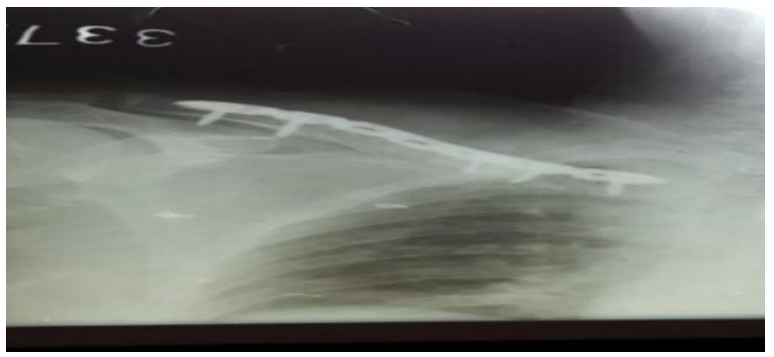

Post- operative x-ray. 


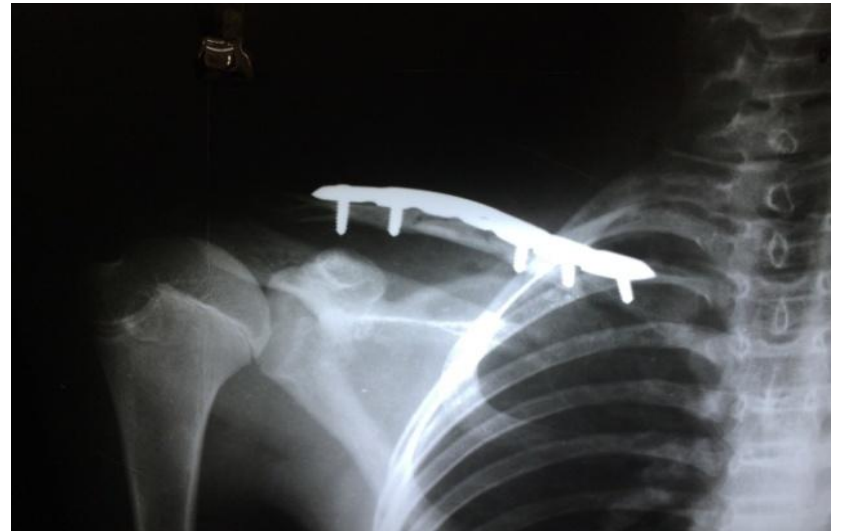

8 weeks post-op x-ray showing union.

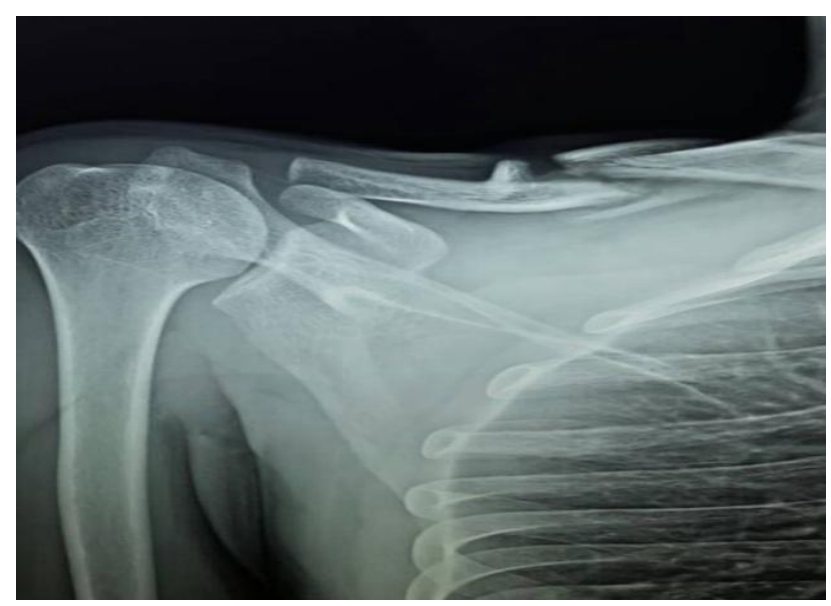

Pre-operative x-ray. ( case no 67 )

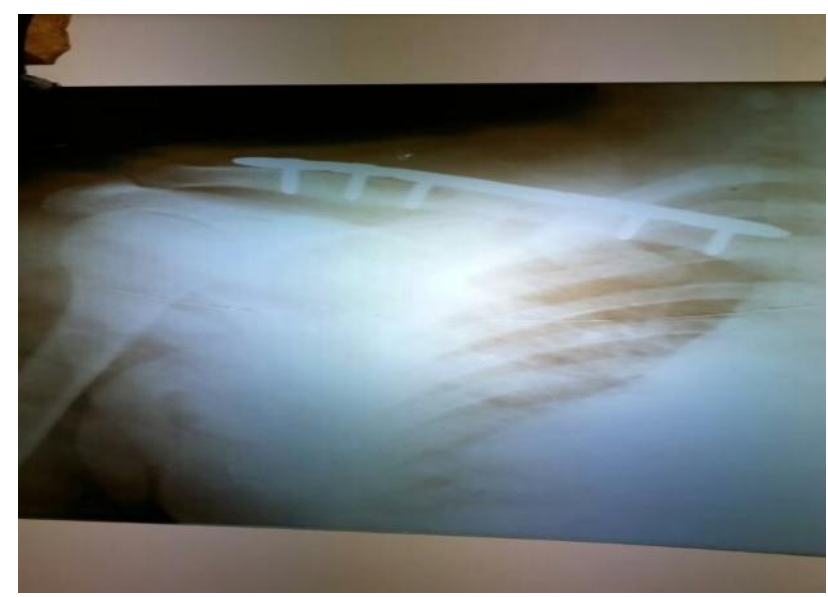

Post-operative $\mathrm{x}$-ray.

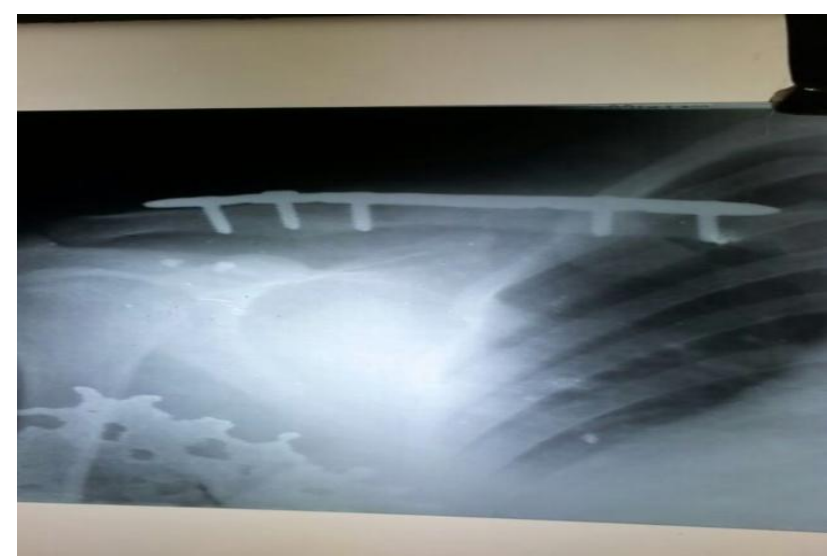

9 weeks post-op x-ray showing union

\section{References}

1. O’Neill BJ, Hirpara KM, O’Briain D, McGarr C, Kaar TK. Clavicle fractures: a comparison of five classification systems and their relationship to treatment outcomes. Int Orthop [Internet]. 2011-2017; 35(6):90914. Available

from: http://www.ncbi.nlm.nih.gov/pubmed/21088834

2. Hübner EJ, Hausschild O, Südkamp NP, Strohm PC. Clavicle fractures--is there a standard treatment? Acta Chir Orthop Traumatol Cech [Internet]. 2011-2017; 78(4):288-96.

Available

from: http://www.ncbi.nlm.nih.gov/pubmed/21888838

3. NEER CS. Nonunion of the clavicle. J Am Med Assoc [Internet]. 1960-2017; 172:1006-11. Available from: http://www.ncbi.nlm.nih.gov/pubmed/14426324

4. Rowe CR. An atlas of anatomy and treatment of midclavicular fractures. Clin Orthop Relat Res [Internet]. 2017; 58:29-42. Available from: http://www.ncbi.nlm.nih.gov/pubmed/5666865

5. Hill JM, McGuire MH, Crosby LA. Closed treatment of displaced middle-third fractures of the clavicle gives poor results. J Bone Jt Surg [Internet]. 1997-2017; 79(4):5379. Available from: http://www.bjj.boneandjoint.org.uk/cgi/doi/10.1302/0301 $-620 X .79 B 4.7529$

6. Nordqvist A, Petersson CJ, Redlund-Johnell I. Midclavicle fractures in adults: end result study after conservative treatment. J Orthop Trauma [Internet]. 2017; 12(8):572-6. Available from: http://www.ncbi.nlm.nih.gov/pubmed/9840792

7. Nowak J, Holgersson M, Larsson S. Sequelae from clavicular fractures are common. Acta Orthop [Internet]. 2005-2017; 76(4):496-502. Available from: http://www.tandfonline.com/doi/full/10.1080/174536705 10041475

8. Ledger M, Leeks N, Ackland T, Wang A. Short malunions of the clavicle: an anatomic and functional study. J shoulder Elb Surg [Internet]. 2005-2017; 14(4):349-54. Available from: http://linkinghub.elsevier.com/retrieve/pii/S10582746040 02678

9. Wick M, Müller EJ, Kollig E, Muhr G. Midshaft fractures of the clavicle with a shortening of more than 2 $\mathrm{cm}$ predispose to nonunion. Arch Orthop Trauma Surg [Internet]. 2001-2017; 121(4):207-11. Available from: http://www.ncbi.nlm.nih.gov/pubmed/11317682

10. B JM, KDC, KS. Midshaft Clavicle Fractures : A Critical Review. 814-21.

11. Narsaria N, Singh AK, Arun GR, Seth RRS. Surgical fixation of displaced midshaft clavicle fractures : elastic intramedullary nailing versus precontoured plating. 2014, $165-71$.

12. Assistant Professor BS, Associate Professor MK, Azhagan KS, Mohankumar Associate Professor CK. Outcome of plate and intramedullary fixation of midshaft clavicle fractures: A search for optimal surgical management. Int J Orthop Sci IJOS [Internet]. 1050 2017; 3(33):1050-61. Available from: www.orthopaper.com

13. Lee YS, Lin CC, Huang CR, Chen CN, Liao WY. Operative treatment of midclavicular fractures in 62 elderly patients: knowles pin versus plate. Orthopedics [Internet]. 2007-2017; 30(11):959-64. Available from: http://www.ncbi.nlm.nih.gov/pubmed/18019991

14. Mudd CD, Quigley KJ, Gross LB. Excessive 
Complications of Open Intramedullary Nailing of Midshaft Clavicle Fractures With the Rockwood Clavicle Pin. Clin Orthop Relat Res [Internet]. 2011-2017; 469(12):3364-70. Available from: http://www.ncbi.nlm.nih.gov/pubmed/21424833

15. Mueller M, Rangger C, Striepens N, Burger C. Minimally Invasive Intramedullary Nailing of Midshaft Clavicular Fractures Using Titanium Elastic Nails. J Trauma Inj Infect Crit Care [Internet]. 2008-2017; 64(6):1528-34. Available from: http://www.ncbi.nlm.nih.gov/pubmed/18545118

16. Alshameeri ZA, Katam K, Alsamaq M, Sonsale P. Original Article The outcome of surgical fixation of mid shaft clavicle fractures; looking at patient satisfaction and comparing surgical approaches. 2012; 6(3):76-81.

17. Vander Have KL, Perdue AM, Caird MS, Farley FA. Operative Versus Nonoperative Treatment of Midshaft Clavicle Fractures in Adolescents. J Pediatr Orthop [Internet]. 2010-2017; 30(4):307-12. Available from: http://www.ncbi.nlm.nih.gov/pubmed/20502227

18. Bajuri MY, Maidin S, Rauf A, Baharuddin M, Harjeet S. Functional outcomes of conservatively treated clavicle fractures. Clinics (Sao Paulo) [Internet]. 2011-2017; 66(4):635-9. Available from: http://www.ncbi.nlm.nih.gov/pubmed/21655759

19. Robertson C, Celestre P, Mahar A, Schwartz A. Reconstruction plates for stabilization of mid-shaft clavicle fractures: Differences between nonlocked and locked plates in two different positions. J Shoulder Elb Surg [Internet]. 2009-2017; 18(2):204-9. Available from: http://www.ncbi.nlm.nih.gov/pubmed/19111476

20. Cho C, Kim DH, Kim B. Radiographic and clinical results of tension suture fi xation using two washers with PHILOS plate for proximal humeral fractures. Injury [Internet]. 2016, 2012. Available from: http://dx.doi.org/10.1016/j.injury.2016.11.030

21. VanBeek C, Boselli KJ, Cadet ER, Ahmad CS, Levine WN. Precontoured Plating of Clavicle Fractures: Decreased Hardware-related Complications? Clin Orthop Relat Res [Internet]. 2011-2017; 469(12):3337-43. Available from: http://link.springer.com/10.1007/s11999011-1868-0

22. Campochiaro G, Tsatsis C, Catani F. Displaced mid-shaft clavicular fractures: surgical treatment with a precontoured angular stability plate. 2012; 96:21-6.

23. Woltz S, Duijff JW, Hoogendoorn JM, Rhemrev SJ, Breederveld RS, Schipper IB et al. Reconstruction plates for midshaft clavicular fractures: A retrospective cohort study. Orthop Traumatol Surg Res [Internet]. 2016; 102(1):25-9. Available from: http://dx.doi.org/10.1016/j.otsr.2015.11.008

24. Lazarides S, Zafiropoulos G. Conservative treatment of fractures at the middle third of the clavicle: the relevance of shortening and clinical outcome. J shoulder Elb Surg [Internet]. 2006, 2017; 15(2):191-4. Available from: http://linkinghub.elsevier.com/retrieve/pii/S10582746050 02314

25. Trial RC. Nonoperative Treatment Compared with Plate Fixation of Displaced Midshaft Clavicular Fractures. 2007, 1-10.

26. For L, Education C. Treatment of Proximal Humeral Fractures - a Review of Current Concepts Enlightened Léčba zlomenin proximálního humeru - přehled současných př́stupů s ohledem. 2012; 2007(8):307-16.

27. Mckee MD. Displaced Clavicle Fractures: Surgery
Provides Better Results. 2016, 2-6.

28. Zlowodzki M, Zelle BA, Cole PA, Jeray K, McKee MD. Evidence-Based Orthopaedic Trauma Working Group. Treatment of acute midshaft clavicle fractures: systematic review of 2144 fractures: on behalf of the EvidenceBased Orthopaedic Trauma Working Group. J Orthop Trauma [Internet]. 2005-2017; 19(7):504-7. Available from: http://www.ncbi.nlm.nih.gov/pubmed/16056089

29. Nowak J, Holgersson M, Larsson S, Torholm C, Rokkanen P. Can we predict long-term sequelae after fractures of the clavicle based on initial findings? A prospective study with nine to ten years of follow-up. J shoulder Elb Surg [Internet]. 1981-2017; 13(5):479-86. Available http://www.ncbi.nlm.nih.gov/pubmed/15383801

30. Nowak J, Holgersson M, Larsson S. Sequelae from clavicular fractures are common: a prospective study of 222 patients. Acta Orthop [Internet]. 2005, 2017; 76(4):496-502. Available from: http://www.tandfonline.com/doi/full/10.1080/174536705 10041475

31. Sankarankutty M, Turner BW. Fractures of the clavicle. Injury [Internet]. 1975-2017; 7(2):101-6. Available from: http://www.ncbi.nlm.nih.gov/pubmed/1205602

32. Chen YF, Wei HF, Zhang C, Zeng BF, Zhang CQ, Xue JF et al. Retrospective comparison of titanium elastic nail (TEN) and reconstruction plate repair of displaced midshaft clavicular fractures. J shoulder Elb Surg [Internet]. 2012-2017; 21(4):495-501. Available from: http://linkinghub.elsevier.com/retrieve/pii/S10582746110 0108X

33. Narsaria N, Singh AK, Arun GR, Seth RRS. Surgical fixation of displaced midshaft clavicle fractures: elastic intramedullary nailing versus precontoured plating. J Orthop Traumatol [Internet]. 2014-2017; 15(3):165-71. Available from: http://link.springer.com/10.1007/s10195014-0298-7

34. Böhme J, Bonk A, Bacher G, Wilharm A, Hoffmann R, Josten C. Aktuelle Behandlungskonzepte der Klavikulaschaftfraktur - Ergebnisse einer prospektiven Multicenterstudie. Z Orthop Unfall [Internet]. 2010-2017 149(1):68-76. Available from: http://www.ncbi.nlm.nih.gov/pubmed/20941694

35. Thyagarajan DS, Day M, Dent C, Williams R, Evans R. Treatment of mid-shaft clavicle fractures: A comparative study. Int J Shoulder Surg [Internet]. 2009-2017; 3(2):23$7 . \quad$ Available from: http://www.ncbi.nlm.nih.gov/pubmed/20661396

36. Ferran NA, Hodgson P, Vannet N, Williams R, Evans RO. Locked intramedullary fixation vs plating for displaced and shortened mid-shaft clavicle fractures: A randomized clinical trial. J Shoulder Elb Surg [Internet]. 2010-2017; 19(6):783-9. Available from: http://www.ncbi.nlm.nih.gov/pubmed/20713274

37. Houwert RM, Wijdicks F. Plate fixation versus intramedullary fixation for displaced mid-shaft clavicle fractures : a systematic review. 2012, 579-85.

38. Celestre P, Roberston C, Mahar A, Oka R, Meunier M, Schwartz A. Biomechanical Evaluation of Clavicle Fracture Plating Techniques: Does a Locking Plate Provide Improved Stability? J Orthop Trauma [Internet]. 2008-2017; 22(4):241-7. Available from: http://www.ncbi.nlm.nih.gov/pubmed/18404033

39. Eskola A, Vainionpää S, Myllynen P, Pätiälä $H$, Rokkanen P. Outcome of clavicular fracture in 89 
patients. Arch Orthop Trauma Surg [Internet]. 19862017; 105(6):337-8. Available from: http://www.ncbi.nlm.nih.gov/pubmed/3813845

40. Formaini N, Taylor BC, Backes J, Bramwell TJ. Superior Versus Anteroinferior Plating of Clavicle Fractures. Orthopedics [Internet]. 2013-2017; 36(7):e898-904. Available from: http://www.ncbi.nlm.nih.gov/pubmed/23823047

41. Ai J, Kan S, Li H, Xu H, Liu Y, Ning G. Anterior inferior plating versus superior plating for clavicle fracture: a meta-analysis. 2017, 1-9.

42. Gheorghiu D, Sinopidis C, Brown DJ. Treatment of Acute Clavicle Fractures with an Anatomical Congruent Clavicle Plate. 2013; 1(2):8-10.

43. Reddy KR, Rathod J, Rao TK. A Study on Surgical Management of Clavicle Midshaft Fractures by Locking Plate. 2016; 3(7):2005-7.

44. Ortho BDMS, Ortho DNB, Orth MC, Kumar D, Ortho NMS, Orth MC et al. Science Direct Open reduction and plating for displaced mid third clavicle fractures e A prospective study. J Clin Orthop Trauma [Internet]. 2013; 4(4):174-9. Available from: http://dx.doi.org/10.1016/j.jcot.2013.09.002

45. Venkatachalam S, Packer G, Sivaji C, Shipton A, Venkatachalam S, Packer G et al. Ispub.com. 2006; $5(1): 1-5$. 